\title{
Numerical simulation of heat transfer to separation tio $/$ water nanofluids flow in an asymmetric abrupt expansion
}

\author{
Cheen Sean Oon ${ }^{1,2, a}$, Sin Nee Yew ${ }^{2}$, Bee Teng $\mathrm{Chew}^{2}$, Kazi Md Salim Newaz ${ }^{2}$, Ahmed Al-Shamma'a $^{1}$, Andy Shaw $^{1}$, \\ Ahmad Amiri ${ }^{2}$ \\ ${ }^{I}$ School of Built Environment, Liverpool John Moores University, Byron Street, Liverpool, L3 3AF, United Kingdom \\ ${ }^{2}$ Department of Mechanical Engineering, University of Malaya, 50603 Kuala Lumpur, Malaysia
}

\begin{abstract}
Flow separation and reattachment of $0.2 \% \mathrm{TiO}_{2}$ nanofluid in an asymmetric abrupt expansion is studied in this paper. Such flows occur in various engineering and heat transfer applications. Computational fluid dynamics package (FLUENT) is used to investigate turbulent nanofluid flow in the horizontal doubletube heat exchanger. The meshing of this model consists of 43383 nodes and 74891 elements. Only a quarter of the annular pipe is developed and simulated as it has symmetrical geometry. Standard k-epsilon second order implicit, pressure based-solver equation is applied. Reynolds numbers between 17050 and 44545 , step height ratio of 1 and 1.82 and constant heat flux of $49050 \mathrm{~W} / \mathrm{m}^{2}$ was utilized in the simulation. Water was used as a working fluid to benchmark the study of the heat transfer enhancement in this case. Numerical simulation results show that the increase in the Reynolds number increases the heat transfer coefficient and Nusselt number of the flowing fluid. Moreover, the surface temperature will drop to its lowest value after the expansion and then gradually increase along the pipe. Finally, the chaotic movement and higher thermal conductivity of the $\mathrm{TiO}_{2}$ nanoparticles have contributed to the overall heat transfer enhancement of the nanofluid compare to the water.
\end{abstract}

\section{Introduction}

Mixing different fine particles in the basefluids has been used as a method to enhance the rate of heat transfer in various heat transfer instruments [1-3]. One of the reasons is due to the thermal conductivity of metal and metal oxide particles exhibits much higher thermal conductivity than those of the basefluids $[4,5]$. However, due to the weak stability of microfluids (the mixing of micro size particle with basefluid), their applications have not been feasible over the past decade. Choking and highpressure drop were considered as the major obstacles of the micro sized particles [6,7]. Recently, nanofluids (mixing of nano sized particle with basefluid) have been widely studied and caught the attention of many researches [8-10]. Because of their promising properties like high thermal conductivity, stable and poor tendency to clog in microchannels, different type of nanofluids have been investigated $[11,12]$.

Shortly after the initial study of nanofluid by Choi [13], numerous researchers have studied the effect of different nanoparticles on the heat transfer performance of heat transfer equipments. Different nanoparticles such as copper oxide $(\mathrm{CuO})$, aluminum oxide $\left(\mathrm{Al}_{2} \mathrm{O}_{3}\right)$, titanium dioxide $\left(\mathrm{TiO}_{2}\right)$ and etc. have been used to produce nanofluids for heat transfer enhancement $[5,14]$. Lee et

\footnotetext{
a Corresponding author: C.S.Oon@2013.1jmu.ac.uk
}

al. [15] experimentally investigated the thermal conductivity of alumina/water, alumina/ethylene glycol and $\mathrm{CuO} /$ ethylene glycol. It is reported $23 \%$ enhancement in the thermal conductivity of ethylene glycol in the presence of $\mathrm{CuO}$ nanoparticles. Murshed et al. [16] did a research in the thermal conductivity of $\mathrm{TiO}_{2}$ water nanofluids. According to the results, there is a strong nonlinear correlation between the thermal conductivity and volume concentration.

Metallic oxide nanoparticles such as $\mathrm{TiO}_{2}, \mathrm{CuO}$ has attracted many researchers in the field of the heat transfer, because of their higher thermal conductivity and good dispersivity in different basefluids such as ethylene glycol, water and oils. Moreover, metals nanoparticles are significantly capable of increasing the thermal conductivity of the basefluids [17]. Due to an increase in the interactions and collisions between the particles and basefluids, the introduction of metal oxide nanoparticles into the common basefluids demonstrates a considerable enhancement in the heat transfer rate of these fluids. Zeinali Heris et al. [17] studied the convective heat transfer coefficient of $\mathrm{Al}_{2} \mathrm{O}_{3} /$ water, $\mathrm{Cu} /$ water, and $\mathrm{CuO} /$ water nanofluids in a circular tube at constant walltemperature condition at laminar flow regime. The results showed that the convective heat transfer coefficient increased as the Peclet number as well as nanoparticle 
concentration increased. Farajollahi et al. [18] obtained the optimal concentration for $\mathrm{TiO}_{2}$ water and $\mathrm{Al}_{2} \mathrm{O}_{3}$-water nanofluids. Nguyen et al. [19] investigated the heat transfer performance of $\mathrm{Al}_{2} \mathrm{O}_{3}$ wwater nanofluids with different sizes and reported that as the size of nanoparticles increased, the heat transfer rates decreased.

On the other hand, some studies confirmed that nanoparticles with low concentration can considerably enhance the thermal conductivity of basefluids [20]. Among different metal oxide nanoparticles, titanium dioxide is selected as a promising and safe nanoparticle for human and is widely utilized for various issues such as biological, nanocomposite, and physical applications $[21,22]$. By looking at chemical activity, $\mathrm{TiO}_{2}$ can prepare a brilliant physical and chemical stability in different basefluids without any surfactant as a stabilizer, which is the main source for reducing extra problems in the thermal equipments. So, $\mathrm{TiO}_{2}$ with an appropriate dispersion can be a good candidate to investigate.

In the current study, a numerical simulation in the presence of $\mathrm{TiO}_{2}$ nanofluid is investigated in an asymmetric abrupt expansion. The thermal performance of $\mathrm{TiO}_{2}$ nanofluid is studied under various step height ratios in a horizontal double tube heat exchanger.

\section{Methodology}

\subsection{Design}

In order to investigate the rate of heat transfer in the presence of $\mathrm{TiO}_{2}$ nanofluid, an asymmetric abrupt expansion is first simulated by computational fluid dynamic software (FLUENT) [23]. As can be seen in Figure 1, the length of the annular pipe is $1300 \mathrm{~mm}$ with an inner diameter of $20 \mathrm{~mm}$. The red line along the outer pipe in the figure indicates the surface area heated at heat flux, q of $49050 \mathrm{~W} / \mathrm{m}^{2}$. The step heights were created by changing the diameter of entrance tube (d) from $60 \mathrm{~mm}$ to $33 \mathrm{~mm}$, which is equivalent to the step height ratios of 1 and 1.82 respectively.

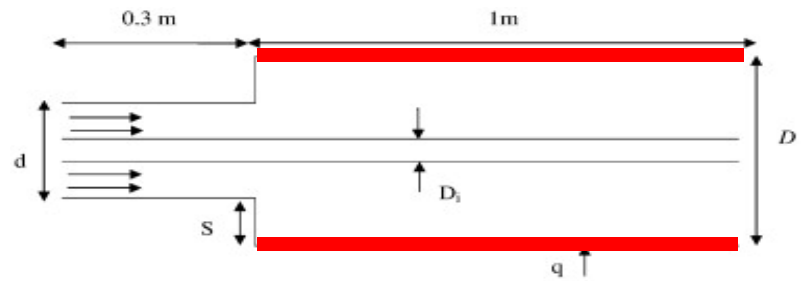

Figure 1. Schematic diagram of flow in an annular pipe with sudden expansion.

Table 1 illustrate the summarized dimensions of test section of the horizontal double-tube heat exchanger with variable steps heights.

Table 1. Dimensions of the model.

\begin{tabular}{|c|c|c|}
\hline $\begin{array}{c}\text { Inner tube } \\
(\mathbf{m m})\end{array}$ & \multicolumn{2}{|c|}{ Annular Test Section (mm) } \\
\hline $\mathrm{D}_{\mathrm{i}}=20$ & $\mathrm{~d}=60$ and 33 & $\mathrm{D}=60$ \\
\hline 1300 & 300 & 1000 \\
\hline
\end{tabular}

\subsection{CFD simulations}

Numerical simulation is utilized to study the Nusselt number, the local heat transfer coefficient and the flow behaviour through sudden expansion in an annular pipe [24]. Figure 2 illustrates the geometry meshed via the FLUENT software. The meshing results include the statistic nodes of 43383 and 74891 elements. Only a quarter of the annular pipe is drawn and simulated due to its symmetrical geometry.
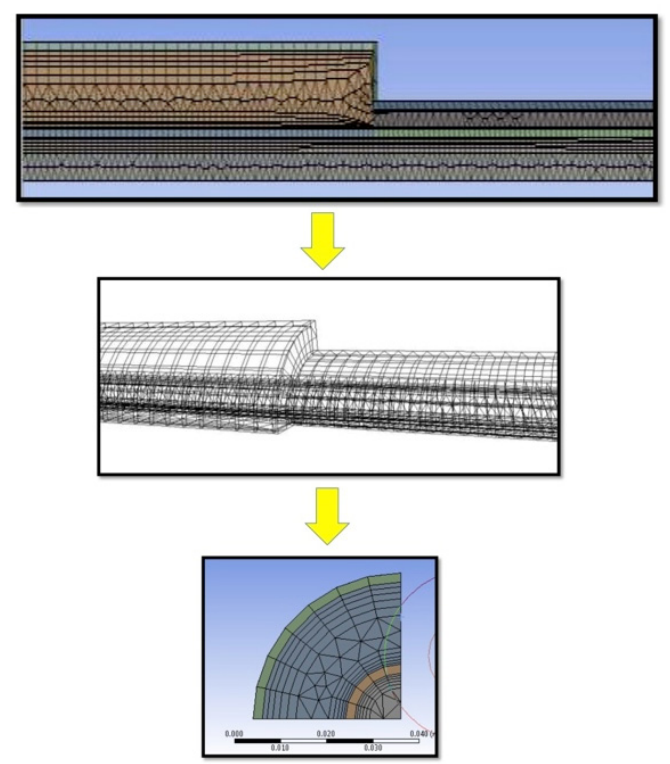

Figure 2. Meshing of the geometry.

Simulations were performed until its residual values drop below $1 \cdot 10^{-4}$. Four distinct Reynolds numbers of $17050,30720,39992$ and 44545 are selected to investigate in the simulation. Obviously these Reynolds numbers imply the fully developed turbulent flow. The boundary condition for the inlet is set as velocity inlet. Both of the momentum and turbulent dissipation rate are interpreted by the second order upwind. Table 2 shows the computational conditions of the numerical simulation. Standard k-epsilon second order implicit, pressure basedsolver equation is applied. The simulated fluid flow is treated as single phase flow rather that multiphase flow, the fluids properties played an important role in this study. Thermophoresis effect is neglected.

Table 2. Computational conditions of the numerical simulations.

\begin{tabular}{|c|c|}
\hline \multicolumn{2}{|c|}{ Computational conditions } \\
\hline Density & $1000 \mathrm{~kg} / \mathrm{m}^{3}$ \\
\hline Viscosity & $\begin{array}{c}1.7894 \cdot 10^{-5} \\
\mathrm{Kg} / \mathrm{m} \cdot \mathrm{s}\end{array}$ \\
\hline Pressure & $101325 \mathrm{~Pa}$ \\
\hline Space/Time & $\begin{array}{c}2 \mathrm{D} / \mathrm{unsteady} \\
\text { second } \\
\text { order implicit }\end{array}$ \\
\hline Residual error & $1 \cdot 10^{-4}$ \\
\hline
\end{tabular}




\begin{tabular}{|c|c|}
\hline Inlet boundary type & Velocity inlet \\
\hline $\begin{array}{c}\text { Outlet boundary } \\
\text { type }\end{array}$ & Pressure outlet \\
\hline Viscous model & $\mathrm{k} \& \varepsilon$ \\
\hline $\begin{array}{c}\text { Interpolating } \\
\text { Scheme (turbulence \& } \\
\text { momentum) }\end{array}$ & $\begin{array}{c}\text { Second-order } \\
\text { upwind }\end{array}$ \\
\hline
\end{tabular}

\subsection{Data processing}

To investigate the influence of the $\mathrm{TiO}_{2}$ on the thermal properties of pure water, the heat transfer coefficient $\left(\mathrm{H}_{\mathrm{x}}\right)$ have been considered. The local heat transfer coefficient $\left(\mathrm{H}_{\mathrm{x}}\right)$ is calculated using Eq. (1).

$$
H_{\mathrm{x}}=q_{\mathrm{c}} /\left(T_{\mathrm{sx}}-T_{\mathrm{bx}}\right)
$$

where $\mathrm{q}_{\mathrm{c}}$ convective heat flux, $\mathrm{T}_{\mathrm{sx}}$ surface temperature and $\mathrm{T}_{\mathrm{bx}}$ local bulk air temperature. Reynolds number can be calculated utilizing the equation (2):

$$
R e_{\mathrm{d}}=\rho_{\mathrm{f}} \cdot U \cdot D_{\mathrm{h}} / \mu_{\mathrm{f}}
$$

where $\rho_{\mathrm{f}}$ density of fluid, $\mathrm{U}$ velocity of fluid, $\mathrm{D}_{\mathrm{h}}$ hydraulic diameter of the annular pipe and $\mu_{\mathrm{f}}$ dynamic viscosity of the bulk fluid. The local Nusselt number $(\mathrm{Nu})$ can be evaluated by Eq. (3):

$$
N u=H_{X} \cdot d / K_{\mathrm{f}}
$$

where $\mathrm{d}$ diameter of pipe and $\mathrm{K}_{\mathrm{f}}$ is the thermal conductivity of bulk fluid.

Table 3 shows the thermal physical properties of $\mathrm{TiO}_{2}$ nanoparticles and water [25]. The nanoparticles are significantly capable of increasing the thermal conductivity of the basefluids as shown in table 3 .

Table 3. Thermal physical properties of $\mathrm{TiO}_{2}$ nanoparticles.

\begin{tabular}{|c|c|c|c|}
\hline Property & $\begin{array}{c}\text { Water as } \\
\text { the base } \\
\text { fluid }\end{array}$ & $\begin{array}{c}\mathbf{T i O}_{\mathbf{2}} \\
\text { nanoparticles }\end{array}$ & $\begin{array}{c}\mathbf{T i O}_{\mathbf{2}} \\
\text { nanofluid } \\
\mathbf{( 0 . 2 \% )}\end{array}$ \\
\hline $\begin{array}{c}\mathrm{Cp}(\text { heat } \\
\text { capacity, } \mathrm{J} / \mathrm{kg} \\
\mathrm{K})\end{array}$ & 4182 & 686.2 & 4175 \\
\hline Density (kg/m $\left.{ }^{3}\right)$ & 998.2 & 4250 & 1004.7 \\
\hline $\begin{array}{c}\text { Thermal } \\
\text { conductivity } \\
(\mathrm{W} / \mathrm{m} . \mathrm{K})\end{array}$ & 0.6 & 8.9538 & 0.6208 \\
\hline
\end{tabular}

Thermal physical properties of nanofluids such as thermal conductivity, specific heat, density and viscocity of nanofluids can be obtained by several suggested correlations. The thermal conductivity of $\mathrm{TiO}_{2}$ nanofluids can be calculated using equation (4) [26]:

$$
K_{\mathrm{nf}}=\underset{\left(\left(K_{\mathrm{p}}+2 K_{\mathrm{bf}}+2 \phi\left(K_{\mathrm{p}}-K_{\mathrm{bf}}\right)(1+\beta)^{3}\right) /\left(K_{\mathrm{p}}+2 K_{\mathrm{bf}}-\right.\right.}{\left.\left.\phi\left(K_{\mathrm{p}}-K_{\mathrm{bf}}\right)(1+\beta)^{3}\right)\right] \cdot K_{\mathrm{bf}}}
$$

where $\mathrm{Knf}$ thermal conductivity of nanofluid, $\mathrm{Kp}$ is the thermal conductivity of nanoparticles, $\mathrm{Kbf}$ thermal conductivity of basefluids and $\beta$ ratio of the nanolayer thickness to the original particle radius. Generally, the value of $\beta=0.1$, is selected in the calculation of the thermal conductivity of nanofluids. Equation (5) is utilized to calculate the density of nanofluids [27]:

$$
\rho_{\mathrm{nf}}=\phi \rho_{\mathrm{p}}+(1-\phi) \rho_{\mathrm{bf}}
$$

where $\phi$ volume fraction of the nanoparticles, $\rho_{\mathrm{bf}}$ density of basefluid and $\rho_{\mathrm{p}}$ density of nanoparticles. Equation (6) is used to calculate the heat capacity of nanofluids [27]:

$$
C p_{\mathrm{nf}}=\phi C p_{\mathrm{p}}+(1-\phi) C p_{\mathrm{bf}}
$$

where $\mathrm{Cp}_{\mathrm{nf}}$ heat capacity of nanofluids, $\mathrm{Cp}_{\mathrm{bf}}$ heat capacity of basefluids and $\mathrm{Cp}_{\mathrm{p}}$ heat capacity of nanoparticles. The viscosity of nanofluids is calculated using equation (7) and only appropriate for the volume fraction less than 5.0 vol.\% [28].

$$
\mu_{\mathrm{nf}}=(1+1.25 \phi) \mu_{\mathrm{bf}}
$$

where $\mu_{\mathrm{nf}}$ viscosity of nanofluids and $\mu_{\mathrm{bf}}$ viscosity of basefluids.

\section{Results and Discussion}

Two different step heights with four different Reynolds numbers are investigated along the test section. The heat flux is chosen $49050 \mathrm{~W} / \mathrm{m}^{2}$. The variations of the surface temperature under the conditions without abrupt expansion with four Reynolds numbers between 17050 and 44545 at the constant heat flux of $49050 \mathrm{~W} / \mathrm{m}^{2}$ are shown in Figure 3. The graph shows an obvious increase of the surface temperature along the pipe. The minimum amount of the surface temperature is obtained at zero distance. Also, the surface temperature curve shows a gradual increase along the first 0.8 meter and afterwards results illustrates a sharp increment until the axial distance of $1.2 \mathrm{~m}$. Finally, the increase of Reynolds number also increases the heat transfer.

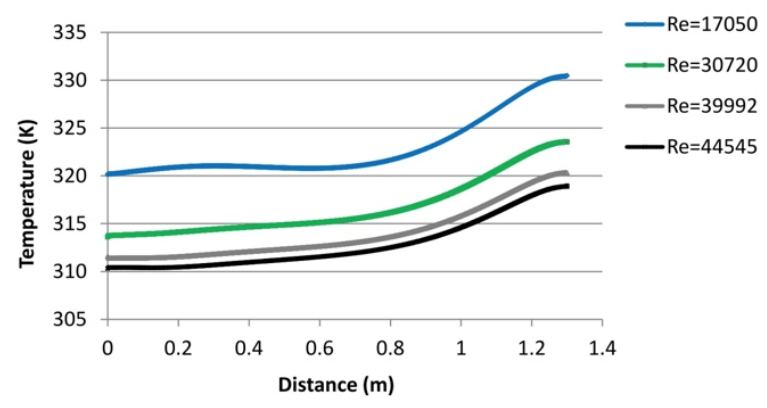

Figure 3. Graphical representation of temperature versus distance for water.

Figure 4 illustrates the distribution of the heat transfer coefficient versus distance for water at zero steps height and constant heat flux of $49050 \mathrm{~W} / \mathrm{m}^{2}$ for various Reynolds numbers. It can be noticed that as the surface temperature increases along the pipe, the values of the 
heat transfer coefficient decreases. In agreement with figure 3 , the curves of the heat transfer coefficient show a gradual decrease along 0.8 meters and then illustrate a sharp drop.

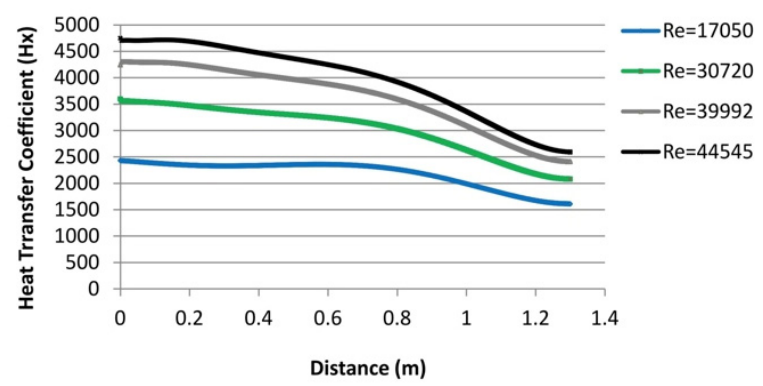

Figure 4. Graph of the heat transfer coefficient versus distance for water.

The distribution of Nusselt numbers versus distance for water at zero step height in the presence of different Reynolds numbers is illustrated in Figure 5. The Nusselt number increases along the pipe and as the Reynolds number increases, Moreover, the curves of the local heat transfer coefficient (Figure 4) and the Nusselt number (Figure 5) show the similar trends at the different Reynolds numbers.

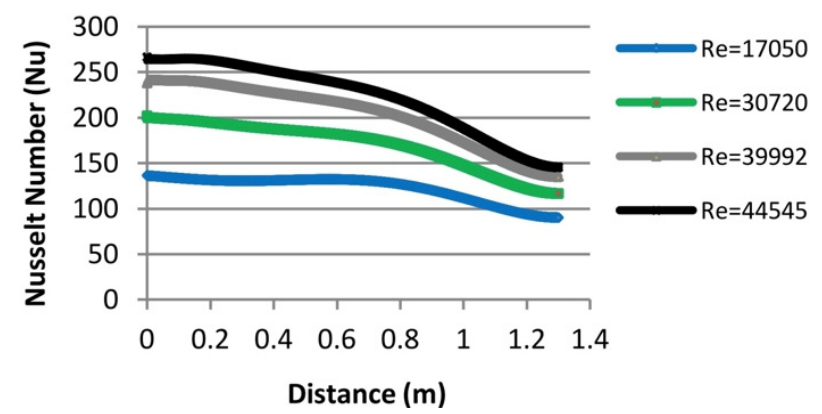

Figure 5. Graph of the Nusselt number versus distance for water.

The variations of surface temperature at the step height ratio of 1.82 with different Reynolds numbers of 17050, 30720, 39992 and 44545 are illustrated in Figure 6 . The results show a sudden decrease in temperature just after the expansion, which follows by a gradual increase along the pipe. The flow reattachment occurs at the lowest temperature point. The overall is obtained surface temperature curves show the highest value at Reynolds number of 17050 but decreases as the Reynolds number increases.

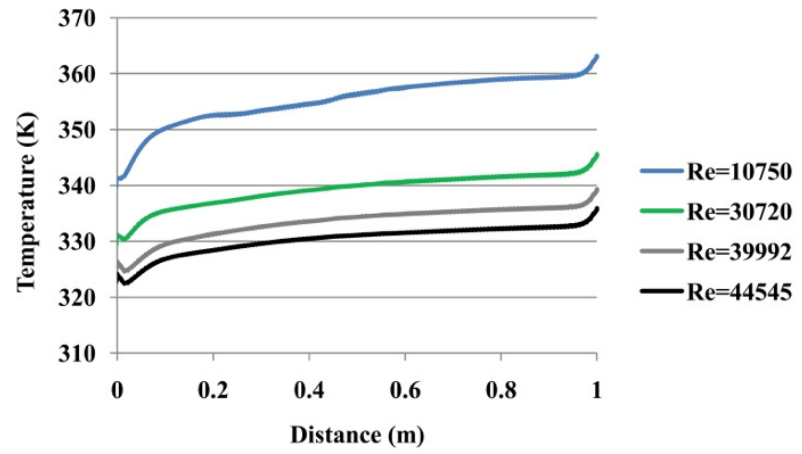

Figure 6. The schematic diagram of temperature versus distance for $\mathrm{TiO}_{2}$ nanofluid.

Figure 7 shows the local heat transfer coefficient versus the distance of water under the same conditions. A sudden growth in the heat transfer coefficient is obvious at $0 \mathrm{~m}$ and all curves at different Reynolds numbers illustrate a downward trend along the pipe after the abrupt expansion. It can be notice that Reynolds number of 44545 results in the maximum extent of the heat transfer coefficient.

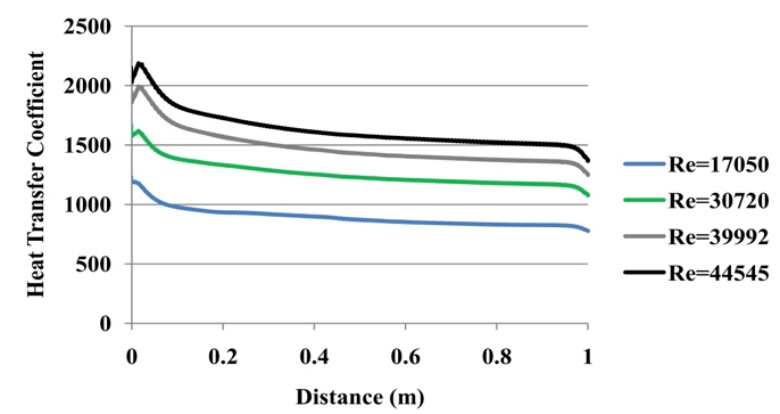

Figure 7. The diagrams of the heat transfer coefficient variation versus distance for $\mathrm{TiO}_{2}$ nanofluid.

The curves of the Nusselt numbers versus distance for water at various Reynolds numbers are demonstrated in Figure 8. As mentioned above, the heat transfer coefficient and the Nusselt number illustrate approximately similar trends at different Reynolds numbers, which are obvious in mentioned figures.

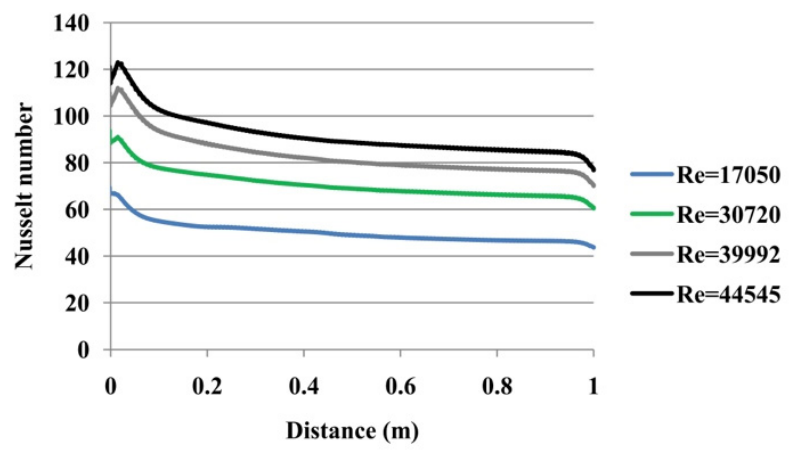

Figure 8. The schematic diagram of Nusselt number versus distance for $\mathrm{TiO}_{2}$ nanofluid.

The schematic diagrams of temperature versus different distance for water as the basefluid and $\mathrm{TiO}_{2}$ 
nanofluid are illustrated in Figure 9. The numerical simulation was conducted at 1.82 step height ratio and Reynolds number of 39992. Temperature curves of the water and $\mathrm{TiO}_{2}$ are shown that there is a considerable drop in temperature as $\mathrm{TiO}_{2}$ utilized. According to the higher thermal conductivity of $\mathrm{TiO}_{2}$ nanofluid rather than that of the basefluid, the lower range of temperature of $\mathrm{TiO}_{2}$ is reasonable.

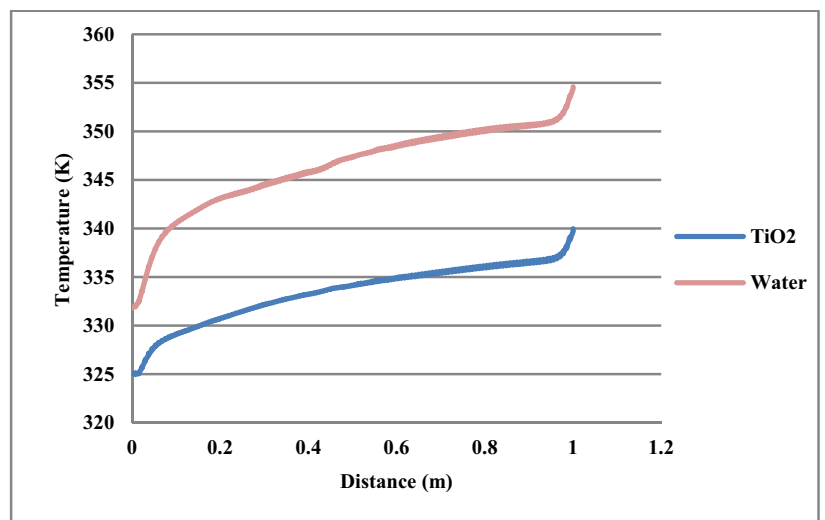

Figure 9. The schematic diagrams of temperature versus distance.

The numerical simulation results of the heat transfer coefficient are shown in different length positions in Figure 10 for water and $\mathrm{TiO}_{2}$ nanofluid. One can see that the heat transfer coefficient curve of $\mathrm{TiO}_{2}$ as well as water illustrate the downward trends. In agreement with Figure 9, as the $\mathrm{TiO}_{2}$ used, the heat transfer coefficient increased noticeably as compared with basefluid. This may be due to the fact that $\mathrm{TiO}_{2}$ itself has a higher thermal conductivity.

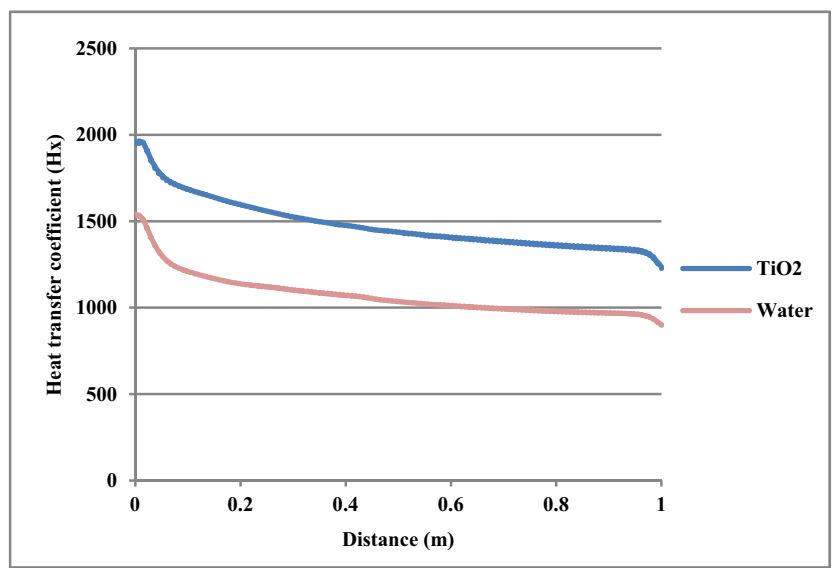

Figure 10. The schematic diagrams of the heat transfer coefficient versus distance.

The schematic diagram of Nusselt number versus distance is shown in Figure 11. There is a good similarity between the schematic curves of the heat transfer coefficient and Nusselt number. Furthermore, the Nusselt number curves of $\mathrm{TiO}_{2}$ and water show downward trends along the pipe. In agreement with Figure 10, $\mathrm{TiO}_{2}$ nanofluid is show higher Nusselt number compared to water as a basefluid, which can be attributed to the higher thermal conductivity of $\mathrm{TiO}_{2}$ in basefluid.

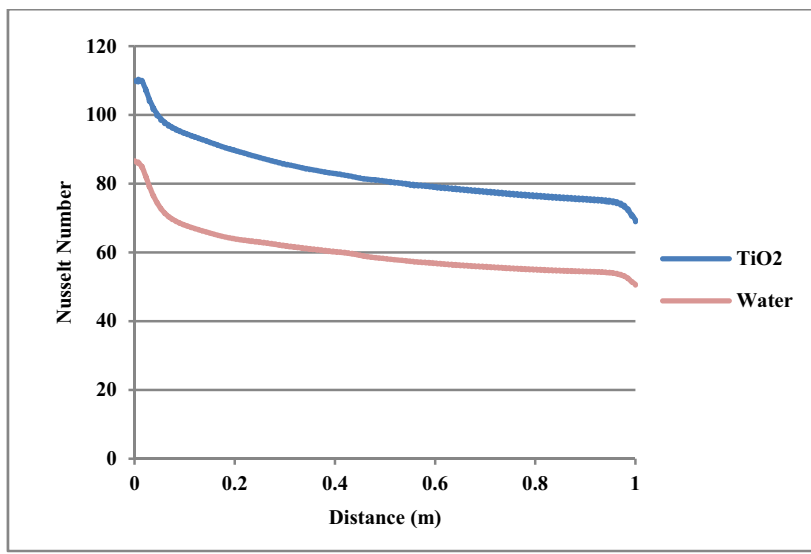

Figure 11. The schematic diagram of Nusselt number versus distance.

\section{Conclusions}

In summary, increase in step height ratio and Reynolds number results in a great increase in the heat transfer coefficient. It is partly due to the interactions and collisions between the particles and basefluids and increase in thermal physical properties of nanofluid. Moreover, the surface temperature will drop to its lowest value after the expansion and then gradually increase along the pipe. The minimum point of the surface temperature indicates the flow recirculation zone or reattachment point. The results also illustrates that the $\mathrm{TiO}_{2}$ nanofluids presents higher heat transfer performance as compared to the water. $\mathrm{TiO}_{2}$ nanofluids show the higher extent of the heat transfer coefficient and Nusselt number at the same condition such as step height ratio and Reynolds number. Finally, the chaotic movement and higher thermal conductivity of the $\mathrm{TiO}_{2}$ nanoparticles have contributed to the overall heat transfer enhancement of the nanofluid compare to the water.

\section{Nomenclature}

$\begin{array}{ll}\mathrm{Cp} & \text { Heat capacity, } \mathrm{J} / \mathrm{kg} \mathrm{K} \\ \mathrm{D} & \text { Diameter, m } \\ \mathrm{H}_{\mathrm{x}} & \text { Heat transfer coefficient, W/m } \mathrm{m}^{2} \mathrm{~K} \\ \mathrm{~K} & \text { Thermal conductivity, W/m K } \\ \mathrm{Nu} & \text { Nusselt number } \\ \mathrm{q} & \text { Heat flux, W/m }{ }^{2} \\ \mathrm{Re} & \text { Reynolds number } \\ \mathrm{T} & \text { Temperature, }{ }^{\circ} \mathrm{C} \\ \mathrm{U} & \text { Velocity, } \mathrm{m} / \mathrm{s} \\ \mathrm{x} & \text { local distance, } \mathrm{m} \\ \mathrm{D}_{\mathrm{h}} & \text { Hydraulic diameter }, \mathrm{m} \\ \mathrm{TiO}_{2} & \text { Titanium dioxide } \\ \mathrm{L} & \text { Length, } \mathrm{m}\end{array}$

\section{Greek symbols}

$\begin{array}{ll}\phi & \text { Volume fraction } \\ \rho & \text { Density, } \mathrm{kg} / \mathrm{m}^{3} \\ \mu & \text { Viscosity, Pa s } \\ \beta & \begin{array}{l}\text { Ratio of the nanolayer thickness to the } \\ \text { original particles radius }\end{array}\end{array}$




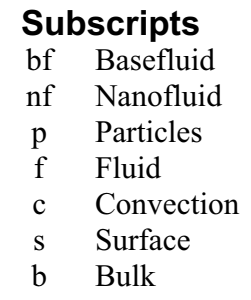

\section{Acknowledgements}

The authors gratefully acknowledge UMRG Grant RP012B-13AET and UM.C/625/1/HIR/MOHE/ENG/45, Faculty of Engineering, University of Malaya, Malaysia for support to conduct this research work.

\section{References}

1. C.S. Oon, A. Badarudin, S.N. Kazi, A. Syazwan, 2013 Fifth Int. Conf. on Computational Intelligence, Modelling and Simulation (CIMSim) (2013)

2. C.S. Oon, H. Togun, S.N. Kazi, A. Badarudin, E. Sadeghinezhad, Int Commun Heat Mass 46, (2013)

3. C.S. Oon, H. Togun, S.N. Kazi, A. Badarudin, M.N.M. Zubir, E. Sadeghinezhad, Int Commun Heat Mass 39, 8 (2012)

4. H. Togun, Y.K. Salman, H.S. Sultan Aljibori, S.N. Kazi, Int J Heat Mass Tran 54, 4 (2011)

5. F. Farzin, S.Z. Heris, S. Rahimi, J. Thermoplast. Compos. Mater 27, 1 (2013)

6. A. Amiri, M. Shanbedi, H. Amiri, S.Z. Heris, S.N. Kazi, B.T. Chew, H. Eshghi, Appl. Therm. Eng 7, 1 (2014)

7. A. Amiri, M. Shanbedi, H. Eshghi, S.Z. Heris, M. Baniadam, J. Phys. Chem. C 116, 5 (2012)

8. M. Kahani, S. Zeinali Heris, S.M. Mousavi, Heat Mass Transfer 50, 11 (2014)

9. H. Zare-Zardini, A. Amiri, M. Shanbedi, M. Memarpoor-Yazdi, A. Asoodeh, Surf. Interface Anal 45, 3 (2013)

10. A. Amiri, M. Memarpoor-Yazdi, M. Shanbedi, H. Eshghi, J Biomed Mater Res A 101A, 8 (2013)

11. C.T. Nguyen, F. Desgranges, N. Galanis, G. Roy, T. Maré, S. Boucher, H. Angue Mintsa, Int J Therm Sci 47, 2 (2008)

12. P. Guardia, A. Riedinger, S. Nitti, G. Pugliese, S. Marras, A. Genovese, M.E. Materia, C. Lefevre, L. Manna, T. Pellegrino, J. Mater. Chem. B 2, (2014)

13. S.U.S. Choi, J.A. Eastman, Enhancing thermal conductivity of fluids with nanoparticles (1995)

14. M.R. Sohel, S.S. Khaleduzzaman, R. Saidur, A. Hepbasli, M.F.M. Sabri, I.M. Mahbubul, Int. J. Heat Mass Transfer 74, (2014)

15. S. Lee, S.U.S. Choi, S. Li, J.A. Eastman, J. Heat Transfer 121, 2 (1999)

16. S.M.S. Murshed, K.C. Leong, C. Yang, International Int J Therm Sci 44, 4 (2005)

17. S. Zeinali Heris, S.G. Etemad, M. Nasr Esfahany, Int Commun Heat Mass 33, 4 (2006)

18. B. Farajollahi, S.G. Etemad, M. Hojjat, Int. J. Heat Mass Transfer 53, 1 (2010)
19. C.T. Nguyen, F. Desgranges, G. Roy, N. Galanis, T. Maré, S. Boucher, H. Angue Mintsa, Int. J. Heat Fluid Flow 28, 6 (2007)

20. S.M. Kwark, R. Kumar, G. Moreno, J. Yoo, S.M. You, Pool boiling characteristics of low concentration nanofluids, Int. J. Heat Mass Transfer 53, 5 (2010)

21. C. Jayaseelan, A.A. Rahuman, S.M. Roopan, A.V. Kirthi, J. Venkatesan, S.-K. Kim, M. Iyappan, C. Siva, Spectrochim. Acta Mol. Biomol. Spectros 107, (2013)

22. O. Tatsuhiko, M. Ankur, Y. Seiji, N. Hisao, B. Mischa, N. Yuki, J. Phys.: Condens. Matter 26, 24 (2014)

23. C.S. Oon, A. Badarudin, S.N. Kazi, M. Fadhli, Simulation of Heat Transfer to Turbulent Nanofluid Flow in an Annular Passage, Adv Mat Res 925, 2 (2014)

24. C.S. Oon, A. Al-Shamma'a, S.N. Kazi, B.T. Chew, A. Badarudin, E. Sadeghinezhad, Int Commun Heat Mass 57, (2014).

25. E. Abu-Nada, Int. J. Heat Fluid Flow 29, 1 (2008)

26. W. Yu, S.U.S. Choi, J. Nanopart. Res 5, 1-2 (2003)

27. B.C. Pak, Y.I. Cho, Exp Heat Transfer 11, 2 (1998)

28. D.A. Drew, Passman, Stephen L, Appl. Math. Sci 135, (1999). 